\title{
Overview of research on fusion genes in prostate cancer
}

\author{
Chunjiao Song ${ }^{1,2}$, Huan Chen $^{3}$ \\ ${ }^{1}$ Medical Research Center, Shaoxing People's Hospital, Shaoxing University School of Medicine, Shaoxing 312000, China; ${ }^{2}$ Shaoxing Hospital, \\ Zhejiang University School of Medicine, Shaoxing 312000, China; ${ }^{3}$ Key Laboratory of Microorganism Technology and Bioinformatics Research of \\ Zhejiang Province, Zhejiang Institute of Microbiology, Hangzhou 310000, China \\ Contributions: (I) Conception and design: C Song; (II) Administrative support: Shaoxing Municipal Health and Family Planning Science and \\ Technology Innovation Project (2017CX004) and Shaoxing Public Welfare Applied Research Project (2018C30058); (III) Provision of study materials \\ or patients: None; (IV) Collection and assembly of data: C Song; (V) Data analysis and interpretation: H Chen; (VI) Manuscript writing: All authors; \\ (VII) Final approval of manuscript: All authors. \\ Correspondence to: Chunjiao Song. No. 568 Zhongxing Bei Road, Shaoxing 312000, China. Email: chunjiaosong@163.com.
}

\begin{abstract}
Fusion genes are known to drive and promote carcinogenesis and cancer progression. In recent years, the rapid development of biotechnologies has led to the discovery of a large number of fusion genes in prostate cancer specimens. To further investigate them, we summarized the fusion genes. We searched related articles in PubMed, CNKI (Chinese National Knowledge Infrastructure) and other databases, and the data of 92 literatures were summarized after preliminary screening. In this review, we summarized approximated 400 fusion genes since the first specific fusion TMPRSS2-ERG was discovered in prostate cancer in 2005. Some of these are prostate cancer specific, some are high-frequency in the prostate cancer of a certain ethnic group. This is a summary of scientific research in related fields and suggests that some fusion genes may become biomarkers or the targets for individualized therapies.
\end{abstract}

Keywords: Prostate cancer; fusion gene; biomarker

Submitted May 09, 2019. Accepted for publication Dec 26, 2019.

doi: $10.21037 /$ tcr.2020.01.34

View this article at: http://dx.doi.org/10.21037/tcr.2020.01.34

\section{Introduction}

Prostate cancer $(\mathrm{PCa})$ was the second most common malignant tumor of men worldwide with 899,000 new cases each year, accounted for $14 \%$ of all cancers. And it was the sixth cause of cancer-related death in men, especially in developed countries $(1,2)$. It had the highest incidence in Australia, Europe and Northern America, and was also high in the African descent, Southern America and the Caribbean regions. In Asia, however, PCa accounted for only $1-10 \%$ of male tumor cases (3). In recent years, the incidence of $\mathrm{PCa}$ in China had been rising dramatically year by year. In Beijing, Shanghai and Guangzhou, the incidence of PCa had surpassed that of male bladder cancer, ranking first among male genitourinary tumors (4).

$\mathrm{PCa}$ was a highly heterogeneous disease including multiple molecular and clinicopathological subtypes. Among them, molecular changes included an important form of genomic alteration-chromosomal rearrangement, which often leaded to gene fusion. With the rapid development of science and technologies, such as next-generation sequencing (NGS), we had a deeper understanding that chromosome rearrangement could lead to the development of disease. Chromosome rearrangement could be divided into two forms. First, the promoter or enhancer of one gene was randomly connected to another proto-oncogene, triggering the activation of the oncogene. For example, immunoglobulin $(I G)$ or T-cell receptor $(T C R)$ gene promoter region was integrated into $M Y C$ proto-oncogene, resulting in $\mathrm{B}$ or $\mathrm{T}$ cell malignant tumor (5). In the other case, the two genes fused through translocation, such as the specific "Philadelphia chromosome" BCR-ABL in chronic myelogenous leukemia (CML) $(6,7)$. At present, the Mitelman Database of Chromosome Aberrations and Gene Fusions in Cancer had included 10,004 gene fusions (8).

In this review, we summarized the fusion genes associated with PCa. As shown in Table 1 and Table S1, we not only 
Table 1 The list of fusion genes in prostate cancer

\begin{tabular}{|c|c|c|c|c|c|}
\hline Fusion gene & Year & Sample & Function & $\begin{array}{l}\text { Validation by } \\
\text { independent } \\
\text { technology }(\mathrm{Y} \text { or } \mathrm{N})\end{array}$ & Reference \\
\hline TMPRSS2-ETV1 & 2005 & Prostate cancer & - & $\mathrm{N}$ & $(9,13,15)$ \\
\hline U19-Eaf2 & 2006 & $\begin{array}{l}\text { Downregulated in advanced } \\
\text { prostate cancer }\end{array}$ & $\begin{array}{l}\text { Its overexpression can markedly } \\
\text { induce apoptosis in prostate } \\
\text { cancer cells and suppresses } \\
\text { xenograft tumor growth }\end{array}$ & $\mathrm{N}$ & $(17,18)$ \\
\hline C15orf21-ETV1 & 2007 & Prostate cancer & - & $\mathrm{N}$ & $(13,19-23)$ \\
\hline HERV-K-ETV1 & 2008 & Prostate cancer & - & $\mathrm{N}$ & $(11,13,19,23)$ \\
\hline HNRPA2B1-ETV1 & 2008 & Prostate cancer & - & $\mathrm{N}$ & $(13,19,20,24)$ \\
\hline CANT1-ETV1/ETV4 & 2008 & Prostate cancer & - & $\mathrm{N}$ & $(20,25)$ \\
\hline HERVK17-ETV1 & 2008 & Prostate cancer & - & $\mathrm{N}$ & $(21,26)$ \\
\hline EST14-ETV1 & 2008 & Prostate cancer & - & $\mathrm{N}$ & $(13,21,24,26,27)$ \\
\hline DDX5-ETV4 & 2008 & Prostate cancer & - & $\mathrm{N}$ & $(15,20)$ \\
\hline FLJ37254-ETV1 & 2008 & Prostate cancer & - & $\mathrm{Y}$ & (20) \\
\hline SLC45A3-ERG & 2008 & Prostate cancer & - & $\mathrm{N}$ & $(20,28-30)$ \\
\hline FOXP1/DDX5-ETV1 & 2009 & Prostate cancer & - & Y & (24) \\
\hline $\begin{array}{l}\text { ZNF577-ZNF649, } \\
\text { ZNF649-ZNF577 }\end{array}$ & 2009 & Prostate cancer & - & $\mathrm{N}$ & $(35,37,38)$ \\
\hline RC3H2-RGS3 & 2009 & VCaP-Met, VCaP & - & $\mathrm{N}$ & $(12,35,39)$ \\
\hline STRN4-GPSN2 & 2009 & Metastatic prostate cancer & - & $\mathrm{Y}$ & (35) \\
\hline MIPOL1-DGKB & 2009 & LNCaP & - & Y & (35) \\
\hline $\begin{array}{l}\text { HJURP-EIF4E2, } \\
\text { INPP4-HJURP }\end{array}$ & 2009 & Prostate cancer & - & Y & (35) \\
\hline LMAN2-AP3S1 & 2009 & VCaP & - & $\mathrm{N}$ & $(12,35,39,40)$ \\
\hline USP10-ZDHHC7 & 2009 & VCaP & - & $\mathrm{N}$ & $(35,39)$ \\
\hline
\end{tabular}

Table 1 (continued) 
Table 1 (continued)

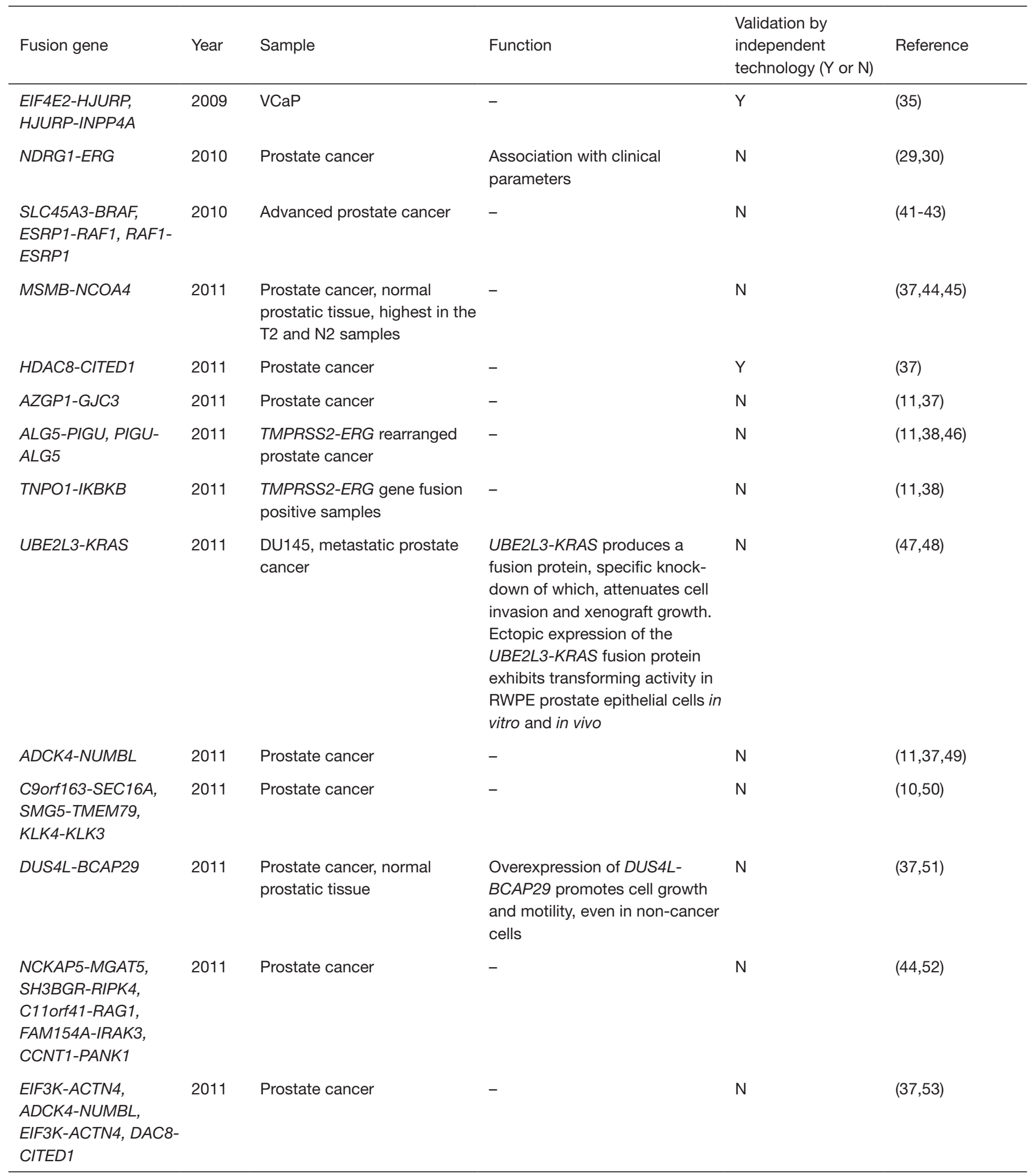

Table 1 (continued) 
Table 1 (continued)

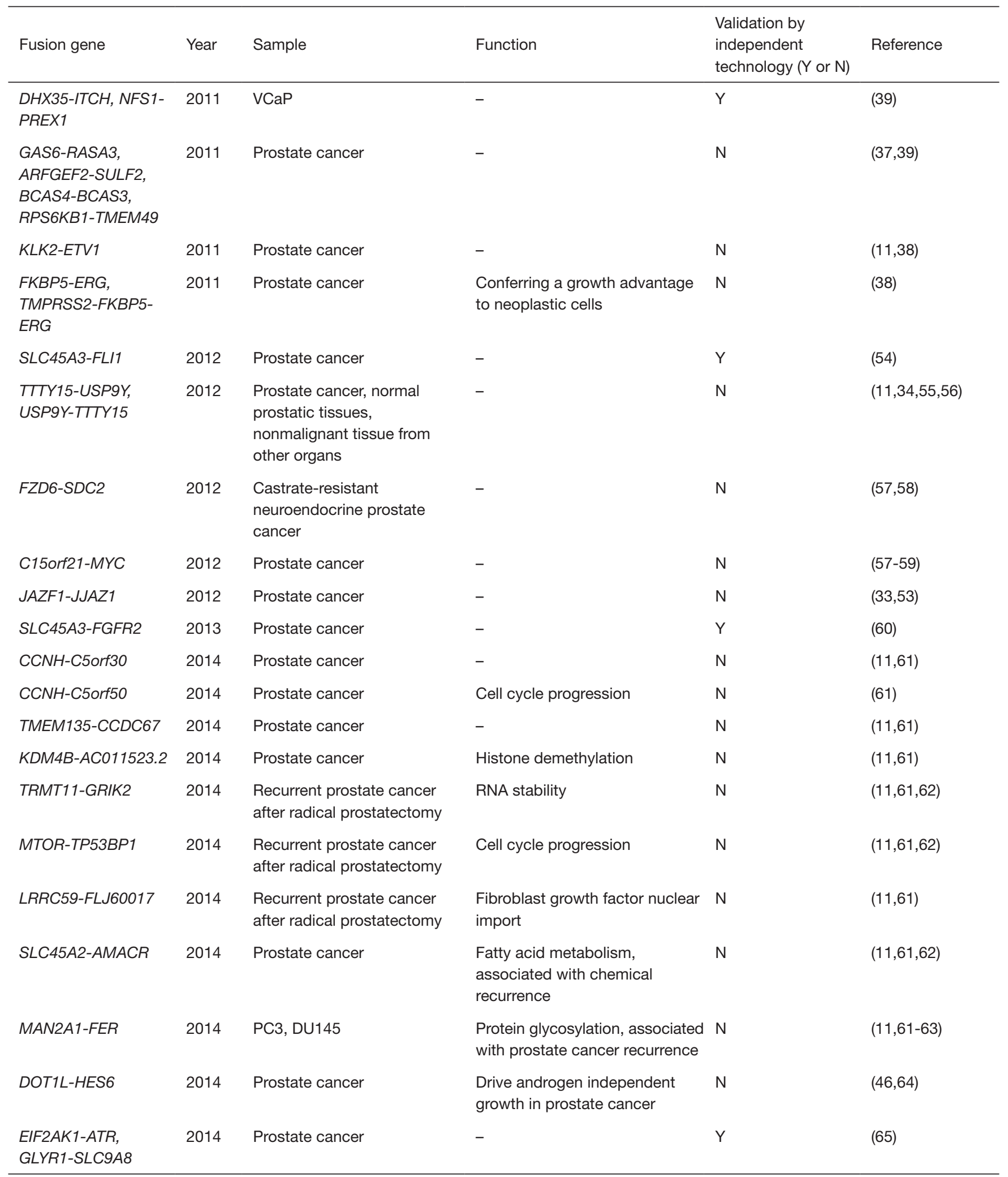

Table 1 (continued) 
Table 1 (continued)

\begin{tabular}{|c|c|c|c|c|c|}
\hline Fusion gene & Year & Sample & Function & $\begin{array}{l}\text { Validation by } \\
\text { independent } \\
\text { technology }(\mathrm{Y} \text { or } \mathrm{N})\end{array}$ & Reference \\
\hline $\begin{array}{l}\text { TMPRSS2-SKIL, } \\
\text { SLC45A3-SKIL, } \\
\text { MIPEP-SKIL, ACPP- } \\
\text { SKIL, HMGN2P46- } \\
\text { SKIL }\end{array}$ & 2015 & ETS-negative prostate cancer & Upregulate the TGF- $\beta$ pathway & $\mathrm{N}$ & $(41,46)$ \\
\hline C14orf80-TMEM121 & 2015 & $\begin{array}{l}\text { Prostate cancer samples, } \\
\text { normal samples }\end{array}$ & - & $\mathrm{N}$ & $(49,53)$ \\
\hline MFGE8-HAPLN3 & 2015 & Prostate cancer & $\begin{array}{l}\text { MFGE8-HAPLN3 had a } \\
\text { correlation with Gleason score. } \\
\text { silencing } D 2 H G D H-G A L 3 S T 2 \\
\text { fusion resulted in dramatic } \\
\text { reduction of cell proliferation } \\
\text { rate and cell motility }\end{array}$ & $\mathrm{N}$ & $(49,53)$ \\
\hline $\begin{array}{l}\text { CLN6-CALML4, } \\
\text { NUDT14-JAG2, } \\
\text { PRIM1-NACA, } \\
\text { SCNN1A-TNFRSF1A, } \\
\text { MBD1-CCDC11 }\end{array}$ & 2015 & Prostate cancer & - & $\mathrm{N}$ & $(49,53)$ \\
\hline $\begin{array}{l}\text { PROM2-KCNIP3, } \\
\text { BAIAP2L2-SLC16A8, } \\
\text { D2HGDH-GAL3ST2 }\end{array}$ & 2015 & LNCaP, RWPE-1 & - & $\mathrm{N}$ & $(49,53)$ \\
\hline SMG5-PAQR6 & 2015 & Prostate cancer & - & $\mathrm{N}$ & $(10,53)$ \\
\hline MPP5-FAM71D & 2015 & PC346C & $\begin{array}{l}\text { Downregulation of } F A M 71 D \\
\text { and MPP5-FAM71D transcripts } \\
\text { in PC346C cells decreased } \\
\text { proliferation }\end{array}$ & $\mathrm{N}$ & (68) \\
\hline ARHGEF3-C8ORF38 & 2015 & G089 & - & $\mathrm{N}$ & $(68)$ \\
\hline $\begin{array}{l}\text { SND1-BRAF, } \\
\text { EPB41L5-PCDP1, } \\
\text { PHF20L1-LRRC6 }\end{array}$ & 2015 & Prostate cancer & $\begin{array}{l}\text { SND1-BRAF may contribute } \\
\text { to the enhanced RAS/RAF/ } \\
\text { MAPK signaling observed } \\
\text { with progression to castration- } \\
\text { resistant prostate cancer }\end{array}$ & $\mathrm{N}$ & (69) \\
\hline
\end{tabular}

Table 1 (continued) 
Table 1 (continued)

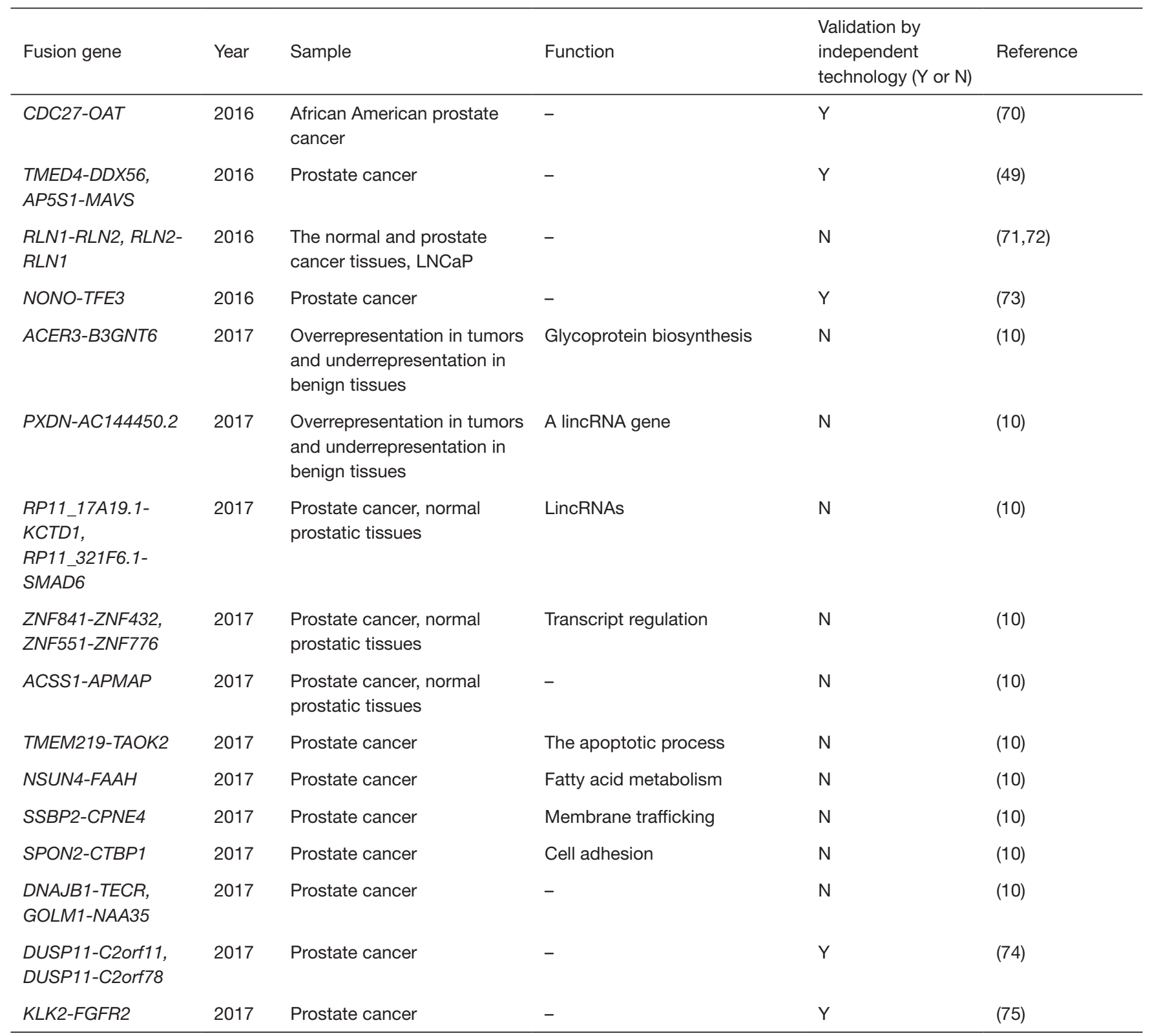

ETS, erythroblast transformation specific; lincRNA, long intergenic non-coding RNA.

listed the fusion genes found in $\mathrm{PCa}$ in order by the year of discovery, but also summarized the types of specimens and the physiological effects and the carcinogenic mechanisms.

\section{TMPRSS2-ERG}

Using the cancer outlier profile analysis (COPA) technique, Tomlins et al. found two new fusion genes in
PCa: TMPRSS2-ERG and TMPRSS2-ETV1, published in the journal "Science" in the Oct 28th, 2005 (9). As a transmembrane serine protease, TMPRSS2 (transmembrane protease serine 2) is expressed in normal prostate cells and PCa cells. TMPRSS2 is located at $21 \mathrm{q} 22.3$, composed of 14 exons and transcribed into a $3.8-\mathrm{kb}$ transcript. TMPRSS2 encodes a protein containing 492 amino acids. The promoter region of TMPRSS 2 has an androgen responsive elements (ARE), and its expression is induced 
by androgen in androgen-sensitive PCa cells (76-78). This type II transmembrane proteinase contains four domains: serine protease domain, cysteine-rich scavenger receptor domain, low-density lipoprotein (LDL) receptor domain and transmembrane domain. TMPRSS2 expression was significantly increased in $\mathrm{PCa}$ and benign prostatic hyperplasia $(\mathrm{BPH})$ tissues, which was correlated with $\mathrm{PCa}$ Gleason score. And TMPRSS2 ectopically expressed in highly malignant $\mathrm{PCa}$, occurring in cytoplasm and cell membrane (79). Erythroblast transformation specific (ETS) transcription factor family includes ERG, ETV1, ETV4 and other members, which are located at 21q22.2, 7p21.2 and $17 \mathrm{q} 21$, respectively. These transcription factors play important roles in many physiological and pathological processes by regulating cell proliferation, differentiation, apoptosis and cell-cell interaction $(9,16)$. ERG (v-ets erythroblastosis virus E26 oncogene homolog) is mainly expressed in mesodermal tissues and a few ectodermal tissues, such as urogenital cells and neural crest cells. ERG contains a highly conserved domain of 85 amino acids, which can bind to the DNA sequence 5 '-GGA(A/T)-3' in the promoter (24). ERG overexpression might promote carcinogenesis by activating c-MYC, and disrupt normal differentiation of prostate epithelial cells (80). Transgenic mice were used to express truncated ERG products encoded by TMPRSS2-ERG. After 12-14 weeks, 3/8 (37.5\%) mice developed into micro-prostate intraepithelial neoplasia (mPIN). These results suggested that ERG could induce prostate neoplasia in mice, supporting its carcinogenic role, but not enough to cause PCa progression (81). However, Kral et al. believed that the fusion of TMPRSS2-ERG/EVTI/ EVT4 could directly increase the chance of cell malignant change and eventually lead to cancerization (82). Therefore, TMPRSS2-ERG fusion gene was considered to be the driver of PCa.

In addition to the $E R G$ and $E T V 1$ genes, other members of the ETS family were also identified as new 3' fusion partners. TMPRSS2-ETV4 fusion gene was found in $\mathrm{PCa}$ with a lower incidence than TMPRSS2-ERG/ETV1 (16). While TMPRSS2-ETVS was also found in PCa by Helgeson's team (19). Besides ERG, ETV1, ETV4 and ETV5, FLI1 was the fifth ETS transcription factor involved in the PCa fusion genes (54) (Table 1).

In 2008, Helgeson's team discovered a novel 5' fusion partner $S L C 45 A 3$ (solute carrier family 45 member 3), forming the fusion gene SLC45A3-ETV5, which was the second most common $5^{\prime}$ fusion partner of ERG except TMPRSS2 (19,28). In 2010, NDRG1 (N-myc downstream regulated gene 1) was also identified as a new 5 ' fusion partner. And the three fusion genes: TMPRSS2-ERG, $S L C 45 A 3-E R G$ and NDRG1-ERG, could lead to the overexpression of the truncated ERG protein $(29,30)$. Subsequently, two new ETV4 fusion genes: KLK2ETV4 and CANT1-ETV4, were reported in PCa $(20,25)$. Both KLK2 (kallikrein related peptidase 2) and CANT1 (calcium activated nucleotidase 1) are androgen-induced and prostate-specific genes (25). Then, two novel fusion genes: OR51E2-ETV1 and UBTF-ETV4, were identified and confirmed by fluorescent in situ hybridization (FISH) and reverse transcription-polymerase chain reaction (RTPCR) in PCa cases (21). Among them, OR51E2 (olfactory receptor, family 51 , subfamily $\mathrm{E}$, member 2 ) encodes a G-protein-coupled receptor. While upstream binding transcription factor $(U B T F)$ is a widely expressed gene, encoding an HMG-box DNA-binding protein involved in the recruitment of RNA polymerase I to ribosomal DNA promoter regions. In addition, HERVK17 $(21,26)$, C15 orf21 (19-22), EST14 (21,24,26,27), 14q133-q21.1 (21), FOXP1 (24), FLJ37254 (20), HERV-K_22q11.23 (19), HNRPA2B1 $(19,20,24)$ and DDX5 $(20,24)$ were identified as $5^{\prime}$ fusion partners of ETS family members (Table 1). In addition, it is well known that TMPRSS2-ERG is a highfrequency fusion gene specifically expressed in $\mathrm{PCa}$ and is a potential biomarker for the diagnosis and prognosis of PCa. We investigated 76 relevant articles to calculate the correlation of TMPRSS2-ERG and PCa patients' features in 2018 (83). The meta-analysis results showed that TMPRSS2-ERG had a highly predictive potential. TMPRSS2-ERG was associated with T-stage, metastasis and Gleason scores of $\mathrm{PCa}$, but not with biochemical recurrence or specific mortality (83).

\section{SLC45A3-ELK4}

SLC45A3 (solute carrier family 45 member 3 ) is a prostate-specific androgen-regulated gene. ELK4 (ETS transcription factor) is a member of the ETS transcription factor family, promoting cell growth in $\mathrm{LNCaP}$ cells. ELK4 was highly expressed in a subgroup of PCa samples compared with benign prostate tissues (10,32). SLC45A3ELK4 fusion was not formed by RNA trans-splicing, but the product of the cis-splicing of adjacent genes (33). The level of the SLC45A3-ELK4 transcript was associated with $\mathrm{PCa}$ progression, and was the highest in metastatic PCa samples (33). The SLC45A3-ELK4 fusion could regulate cell growth by the exogenous expression of the fusion (33). 
Moreover, similar to other long intergenic non-coding RNA (lincRNA) molecules, the fusion RNA was enriched in the nuclear fraction (33).

\section{MSMB-NCOA4}

MSMB-NCOA4 fusion had been found by Nacu et al. (37), and its expression level had been confirmed in PCa and normal prostate tissues $(44,45)$. The $M S M B-N C O A 4$ fusion was transcribed at very low level in $\mathrm{PCa}$, regulated by androgen (45). The MSMB (beta-microseminoprotein) is one of immunoglobulin superfamily, located at chromosome 10q11.2. MSMB is synthesized and secreted into seminal plasma by prostate epithelial cells. NCOA4 (nuclear receptor co-activator 4) locates adjacent to $M S M B$ gene, and its expression product directly interacts with androgen receptor (AR) to promote AR transcriptional activity. Functional experiments showed that the MSMB-NCOA4 fusion gene was related to the AR signaling pathway.

\section{MAN2A1-FER}

The MAN2A1-FER fusion produced a chimera of 954 amino acids, including the $\mathrm{N}$-terminal glycoside hydrolase domain and the mannosidase domain from MAN2A1 and the tyrosine protein kinase domain from FER (11,61-63). Oncogene FER was a tyrosine kinase, and its overexpression was associated with the poor prognosis of several cancers. Many studies showed that FER activated AR and NF- $\mathrm{KB}$ signal pathways (84). In addition, the signal peptide of MAN2A1 (mannosidase a class 2A member) might bring the $M A N 2 A 1-F E R$ fusion product to the Golgi matrix, which might cause the abnormal phosphorylation of glycoproteins to alter multiple signaling pathways in Golgi (11).

\section{SLC45A2-AMACR}

SLC45A2-AMACR fusion resulted in a chimera protein that contained transmembrane domains from SLC45A2 and the intact racemase domain from AMACR $(11,61,62)$. SLC45A2 (solute carrier family 45 member 2 ) is a solute carrier involved in melanin metabolism. AMACR (alphamethylacyl-CoA racemase) is a kind of racemase that participates in branch fatty acid metabolism. AMACR has a mitochondrial localization signal peptide in its $\mathrm{N}$-terminus. While the SLC45A2-AMACR fusion product had a signal peptide from SLC45A2, which located the chimeric protein in membranes and cytoplasm. The ectopic expression of racemase might affect fatty acid-related signaling, which could lead to a variety of cancers. It was noteworthy that SLC45A2-AMACR fusion was associated with PCa chemical recurrence, and tumors with this fusion gene had the most aggressive clinicopathological features (62).

\section{USP9Y-TTTY15, CTAGE5-KHDRBS3, SDK1-AMACR and RAD50-PDLIM4}

In 2012, Ren et al. found USP9Y-TTTY15 fusion $(19 / 54=35.2 \%)$ in Chinese PCa patients by RT-PCR (55). In 2014, Ren et al. also detected the USP9Y-TTTY15 fusion in 105 pairs of $\mathrm{PCa}$ and adjacent normal tissues. They found that the expression level of USP9Y-TTTY15 fusion was not higher in PCa tissues than that in adjacent normal tissues, and was not associated with the characteristics of advanced PCa (34). In 2015, Zhu et al. calculate the TTTY15-USP9Y score using data from 226 urine sediment samples (56). It was found that the TTTY15-USP9Y score was significantly higher in men with positive biopsy results than in men with negative biopsy results $(\mathrm{P}<0.001)$. And the TTTY15USP9Y score significantly increased the diagnostic rate of PCa $(\mathrm{P}=0.001)$ (56). The high-frequency of the USP9YTTTY15 fusion suggested that it might be a physiologic event and plays an important role in the development of $\mathrm{PCa}$ in the Chinese populations $(11,55)$.

USP9Y (ubiquitin specific peptidase 9 Y-linked) encodes an ubiquitin-specific protease involved in spermatogenesis related to male infertility, while TTTY15 (testisspecific transcript, Y-linked 15) is a non-coding RNA (ncRNA) (11). Both USP9Y and TTTY15 are located on the $\mathrm{Y}$ chromosome and are close to each other (34). Interestingly, the transcript of the USP9Y-TTTY15 fusion had not open reading frames (ORF), indicating that this fusion did not encode a functional protein but a testisspecific ncRNA (34,55).

In addition, Ren et al. also found three additional gene fusions: CTAGE5-KHDRBS3 (20/54=37.0\%), SDK1-AMACR $(13 / 54=24.1 \%)$, and RAD50-PDLIM4 (15/54=27.8\%), occurred frequently in Chinese PCa cases, suggesting that these gene fusions might play vital roles in PCa cases in China (55). More than that, Ren et al. also found two other fusion transcripts encoding ncRNA: PHF17-SNHG8 and DYRK1A-CMTM4 (55). Overall, these findings suggested the differences of the PCa gene fusions were existed in different ethnic populations, and supported the idea that genomic rearrangements might be influenced by environmental factors. 


\section{CDC27-OAT}

African-American men were twice as likely as men from other ancestries to develop and die of PCa. Lindquist $e t$ al. sequenced $24 \mathrm{PCa}$ specimens from African-American men, and found that only $21 \%$ and $8 \%$ of the AfricanAmerican patients had TMPRSS2-ERG fusions and PTEN losses, far lower than those of European ancestry (70). They also identified the specific or more common mutations in African-American patients, such as the new fusion gene: $C D C 27$ (cell division cycle 27)-OAT (ornithine aminotransferase), occurring in $17 \%$ of patients (70). This meant that African-American men with more aggressive phenotype $\mathrm{PCa}$ were different from other races at the genomic level, which reinforced the significance of molecular changes in $\mathrm{PCa}$ progression.

\section{TMPRSS2-FKBP5-ERG}

In addition to the more common fusion genes mentioned above, the researchers also found a rare and complex fusion gene TMPRSS2-FKBP5-ERG in PCa. This complex fusion involved the translocation and fusion of three genes, and its expression product promoted the growth of neoplastic cells (38).

\section{Non-coding fusion gene}

PCa-related fusion genes could be divided into several categories according to function. The first category was kinase fusion genes, including: RET, NTRK1, NTRK3, ALK, ROS1, FGFR1/2/3, CRAF, MAST1/2, RAF family and serine/threonine kinase, etc. They had therapeutic importance, considered as the targets for treatment. The second classification was transcription factors: ETS, NUT/ UTM1, POU5F1, MAML2, NFIB, PLAG1, TFE3, NOTCH, and PAX8, causing abnormal expression of downstream target genes in a variety of cancers. The third classification was signaling pathway protein: Wnt/catenin pathway, TGF- $\beta$ pathway, etc. Other categories included growth factor receptors (GABBR2, ITPR2 and TACSTD2), co-factors (GAB2 and WIF1), chromatin modifier genes (histone demethylase and histone methyltransferase), cytoskeletal proteins (MYO19, SEC22B, SNF8, STXBP4, HIP1R and TPR), and metabolic enzymes, etc. Furthermore, there were also some fusions that could lead to loss of function of genes, most of which involved tumor suppressor genes, such as TP53 and PTEN (41).
We had mentioned three non-coding fusion genes in the above: USP9Y-TTTY15, PHF17-SNHG 8 and DYRK1ACMTM4. In 2015, Luo et al. found two MALAT1 fusions: MALAT1-WDR74 and MALAT1-TTN, from a 21-yearold man prostate. MALAT1 (metastasis associated lung adenocarcinoma transcript 1) is a long ncRNA, involved in RNA recombination and located at the active transcription regions. MALAT1 had the oncogenic activity, and its overexpression was associated with the poor prognosis of several malignant tumors (11). The occurrence of MALAT1WDR74 fusion eliminated the translation initiation codonATG. Therefore, the fusion gene did not have any protein products (11). In addition, Zhao et al. also found that two fusion genes: RP11_17A19.1-KCTD1 and RP11_321F6.1$S M A D 6$, which were predicted to encode lincRNAs, not proteins (10).

\section{Discussion}

Throughout history, advances in science and technologies tend to bring new discoveries. As the advent of NGS techniques, the discovery of a large number of fusion genes is spawned. For the discovery of fusion genes, it is conceivable that transcriptome sequencing is more effective than genome sequencing. However, each highthroughput sequencing generates a large amount of data to be analyzed, so we need to develop the reliable and efficient computational methods for detecting gene fusions from RNA-seq data. Nowadays, several tools had been developed to detect large-scale chromosomal rearrangements. These tools included deFuse $(10,85)$, InFusion (12), FusionMap (67), FusionSeq $(41,86)$, FusionCatcher (87), SOAPfuse $(34,88)$, TopHat-Fusion (39), ChimeraScan (89) and SlideSort-BPR (breakpoint reads) $(90,91)$.

One of the foundations of these tools was to find the breakpoints of the cancer genome by mapping to the reference genome. One major drawback of this method was that the variation of the reference genome was so huge. Fusionseq $(38,86)$ was the first computational tool to reveal fusion genes using RNA-seq data. This method was based on the recognition of discordantly read pairs, which was used to construct the connection libraries for possible exon fusion. Then, the reads would be re-adjusted to the construction library to find its fused connection point. If there was not a reference genome, we could detect breakpoints by comparing two assembled genomes. TopHat-Fusion (39) was an effective tool to discover 
fusion genes without the existing annotations. Because it was independent of the gene annotations, TopHat-Fusion could find known fusion products, unknown genes, and unannotated splicing variants (39). In addition, SlideSortBPR (breakpoint reads) $(90,91)$ detected breakpoints by directly comparing data from two different type cells, without mapping them to the reference genomes or without the assembling reads. SlideSort-BPR identified the reads associated with the breakpoints by looking for "unbalanced" reads between the two sets of samples (90).

In conclusion, with the rapid development of science and technology, especially the high-throughput secondgeneration sequencing technology and bioinformatics algorithm, the discovery of fusion genes has ushered in an era of rapid development. Furthermore, to identify fusion genes that have the potential to drive carcinogenesis, scientists need to conduct in-depth studies on the role of fusion genes in cancer. On the one hand, it is necessary to confirm that the fusion genes are specifically expressed in $\mathrm{PCa}$; on the other hand, it is necessary to look for the correlation between these fusion genes and the occurrence and development of PCa. Moreover, it is necessary to explore the molecular mechanism of their promotion of the progression of $\mathrm{PCa}$. The content of this paper was the first step of these in-depth studies, summarizing the fusion genes that have been found to be expressed in PCa.

\section{Conclusions}

To sum up, the formation of fusion genes is one of the important mechanisms to promote the development of $\mathrm{PCa}$. Today, the advance of high-throughput sequencing has led to the discovery of many fusion genes. However, the discovery of PCa-specific fusion genes is lagging far behind the discovery of chromosomal abnormalities. Moreover, many fusion genes exist not only in cancer tissues, but also in benign tissues. In this review, we summarize the fusion genes found in $\mathrm{PCa}$, some of which are $\mathrm{PCa}$-specific fusion genes, and some are the fusion genes of high-frequency in the certain ethnic PCa. These specific fusion genes have great clinical value, not only to diagnose $\mathrm{PCa}$ as biomarkers, but also to inhibit the progression of $\mathrm{PCa}$ as the targets of biological agents.

\section{Clinical significance}

The paper summarized more than 400 fusion genes that had been found in PCa. Some of these were expressed specifically in PCa, and most of them indicated the subtype or the stage of PCa. The discovery of these specific fusion genes which could be used as biomarkers or drug targets, was greatly conducive to the clinical diagnosis and personalized treatment of $\mathrm{PCa}$.

\section{Acknowledgments}

Funding: This work was supported by Zhejiang Provincial Science Technology Program of China (No. 2013C33101), Zhejiang Medical Platform Program (No. 2015RCA023), Shaoxing Municipal Health and Family Planning Science and Technology Innovation Project (No. 2017CX004) and Shaoxing Public Welfare Applied Research Program (No. 2018C30058).

\section{Footnote}

Conflicts of Interest: Both authors have completed the ICMJE uniform disclosure form (available at http://dx.doi. org/10.21037/tcr.2020.01.34). The authors have no conflicts of interest to declare.

Ethical Statement: The authors are accountable for all aspects of the work in ensuring that questions related to the accuracy or integrity of any part of the work are appropriately investigated and resolved.

Open Access Statement: This is an Open Access article distributed in accordance with the Creative Commons Attribution-NonCommercial-NoDerivs 4.0 International License (CC BY-NC-ND 4.0), which permits the noncommercial replication and distribution of the article with the strict proviso that no changes or edits are made and the original work is properly cited (including links to both the formal publication through the relevant DOI and the license). See: https://creativecommons.org/licenses/by-nc-nd/4.0/.

\section{References}

1. Jemal A, Bray F, Center MM, et al. Global cancer statistics. CA Cancer J Clin 2011;61:69-90.

2. Siegel RL, Miller KD, Jemal A. Cancer statistics, 2018. CA Cancer J Clin 2018;68:7-30.

3. Sim HG, Cheng CW. Changing demography of prostate cancer in Asia. Eur J Cancer 2005;41:834-45.

4. Han SJ, Zhang SW, Chen WQ, et al. Analysis of the status and trends of prostate cancer incidence in China. Chinese 
Clinical Oncology 2013;18:330-4.

5. Rabbitts TH. Chromosomal translocations in human cancer. Nature 1994;372:143-9.

6. Rowley JD. Letter: A new consistent chromosomal abnormality in chronic myelogenous leukaemia identified by quinacrine fluorescence and Giemsa staining. Nature 1973;243:290-3.

7. de Klein A, van Kessel AG, Grosveld G, et al. A cellular oncogene is translocated to the Philadelphia chromosome in chronic myelocytic leukaemia. Nature 1982;300:765-7.

8. Mitelman F, Johansson B, Mertens FE. Mitelman Database of Chromosome Aberrations and Gene Fusions in Cancer. Cancer Genome Anatomy Project; 2014. Available online: https://mitelmandatabase.isb-cgc.org/

9. Tomlins SA, Rhodes DR, Perner S, et al. Recurrent fusion of TMPRSS2 and ETS transcription factor genes in prostate cancer. Science 2005;310:644-8.

10. Zhao S, Løvf M, Carm KT, et al. Novel transcriptioninduced fusion RNAs in prostate cancer. Oncotarget 2017;8:49133-43.

11. Luo JH, Liu S, Zuo ZH, et al. Discovery and Classification of Fusion Transcripts in Prostate Cancer and Normal Prostate Tissue. Am J Pathol 2015;185:1834-45.

12. Okonechnikov K, Imai-Matsushima A, Paul L, et al. InFusion: Advancing Discovery of Fusion Genes and Chimeric Transcripts from Deep RNA-Sequencing Data. PLoS One 2016;11:e0167417.

13. Kumar-Sinha C, Tomlins SA, Chinnaiyan AM. Recurrent gene fusions in prostate cancer. Nat Rev Cancer 2008;8:497-511.

14. Mani RS, Tomlins SA, Callahan K, et al. Induced chromosomal proximity and gene fusions in prostate cancer. Science 2009;326:1230.

15. Brenner JC, Chinnaiyan AM. Translocations in epithelial cancers. Biochim Biophys Acta 2009;1796:201-15.

16. Tomlins SA, Mehra R, Rhodes DR, et al. TMPRSS2:ETV4 gene fusions define a third molecular subtype of prostate cancer. Cancer Res 2006;66:3396-400.

17. Hahn J, Xiao W, Jiang F, et al. Apoptosis induction and growth suppression by U19/Eaf2 is mediated through its ELL-binding domain. Prostate 2007;67:146-53.

18. Xiao W, Jiang F, Wang Z. ELL binding regulates U19/ Eaf2 intracellular localization, stability, and transactivation. Prostate 2006;66:1-12.

19. Helgeson BE, Tomlins SA, Shah N, et al. Characterization of TMPRSS2:ETV5 and SLC45A3:ETV5 gene fusions in prostate cancer. Cancer Res 2008;68:73-80.
20. Han B, Mehra R, Dhanasekaran SM, et al. A fluorescence in situ hybridization screen for E26 transformation-specific aberrations: identification of DDX5-ETV4 fusion protein in prostate cancer. Cancer Res 2008;68:7629-37.

21. Barros-Silva JD, Paulo P, Bakken AC, et al. Novel 5' fusion partners of ETV1 and ETV4 in prostate cancer. Neoplasia 2013;15:720-6.

22. Tomlins SA, Laxman B, Dhanasekaran SM, et al. Distinct classes of chromosomal rearrangements create oncogenic ETS gene fusions in prostate cancer. Nature 2007;448:595-9.

23. Attard G, Clark J, Ambroisine L, et al. Heterogeneity and clinical significance of ETV1 translocations in human prostate cancer. Br J Cancer 2008;99:314-20.

24. Clark JP, Cooper CS. ETS gene fusions in prostate cancer. Nat Rev Urol 2009;6:429-39.

25. Hermans KG, Bressers AA, van der Korput HA, et al. Two unique novel prostate-specific and androgen-regulated fusion partners of ETV4 in prostate cancer. Cancer Res 2008;68:3094-8.

26. Hermans KG, van der Korput HA, van Marion R, et al. Truncated ETV1, fused to novel tissue-specific genes, and full-length ETV1 in prostate cancer. Cancer Res 2008;68:7541-9.

27. Gasi D, van der Korput HA, Douben HC, et al. Overexpression of full-length ETV1 transcripts in clinical prostate cancer due to gene translocation. PLoS One 2011;6:e16332.

28. Perner S, Rupp NJ, Braun M, et al. Loss of SLC45A3 protein (prostein) expression in prostate cancer is associated with SLC45A3-ERG gene rearrangement and an unfavorable clinical course. Int J Cancer 2013;132:807-12.

29. Svensson MA, Perner S, Ohlson AL, et al. A comparative study of ERG status assessment on DNA, mRNA, and protein levels using unique samples from a Swedish biopsy cohort. Appl Immunohistochem Mol Morphol 2014;22:136-41.

30. Esgueva R, Perner S, J LaFargue C, et al. Prevalence of TMPRSS2-ERG and SLC45A3-ERG gene fusions in a large prostatectomy cohort. Mod Pathol 2010;23:539-46.

31. Jun L, Ke S, Zhaoming W, et al. Primary synovial sarcoma of the prostate: report of 2 cases and literature review. Int J Surg Pathol 2008;16:329-34.

32. Rickman DS, Pflueger D, Moss B, et al. SLC45A3-ELK4 is a novel and frequent erythroblast transformationspecific fusion transcript in prostate cancer. Cancer Res 
2009;69:2734-8.

33. Zhang Y, Gong M, Yuan H, et al. Chimeric transcript generated by cis-splicing of adjacent genes regulates prostate cancer cell proliferation. Cancer Discov 2012;2:598-607.

34. Ren G, Zhang Y, Mao X, et al. Transcription-mediated chimeric RNAs in prostate cancer: time to revisit old hypothesis? OMICS 2014;18:615-24.

35. Maher CA, Kumar-Sinha C, Cao X, et al. Transcriptome sequencing to detect gene fusions in cancer. Nature 2009;458:97-101.

36. Qin F, Zhang Y, Liu J, et al. SLC45A3-ELK4 functions as a long non-coding chimeric RNA. Cancer Lett 2017;404:53-61.

37. Nacu S, Yuan W, Kan Z, et al. Deep RNA sequencing analysis of readthrough gene fusions in human prostate adenocarcinoma and reference samples. BMC Med Genomics 2011;4:11.

38. Pflueger D, Terry S, Sboner A, et al. Discovery of nonETS gene fusions in human prostate cancer using nextgeneration RNA sequencing. Genome Res 2011;21:56-67.

39. Kim D, Salzberg SL. TopHat-Fusion: an algorithm for discovery of novel fusion transcripts. Genome Biol 2011;12:R72.

40. Teles Alves I, Hiltemann S, Hartjes T, et al. Gene fusions by chromothripsis of chromosome $5 \mathrm{q}$ in the $\mathrm{VCaP}$ prostate cancer cell line. Hum Genet 2013;132:709-13.

41. Kumar-Sinha C, Kalyana-Sundaram S, Chinnaiyan AM. Landscape of gene fusions in epithelial cancers: seq and ye shall find. Genome Med 2015;7:129.

42. Nakagawa H. Prostate cancer genomics by highthroughput technologies: genome-wide association study and sequencing analysis. Endocr Relat Cancer 2013;20:R171-81.

43. Palanisamy N, Ateeq B, Kalyana-Sundaram S, et al. Rearrangements of the RAF kinase pathway in prostate cancer, gastric cancer and melanoma. Nat Med 2010;16:793-8.

44. Lou H, Li H, Yeager M, et al. Promoter variants in the MSMB gene associated with prostate cancer regulate MSMB/NCOA4 fusion transcripts. Hum Genet 2012;131:1453-66.

45. Sjöblom L, Saramäki O, Annala M, et al. Microseminoprotein-Beta Expression in Different Stages of Prostate Cancer. PLoS One 2016;11:e0150241.

46. Annala M, Kivinummi K, Tuominen J, et al. Recurrent SKIL-activating rearrangements in ETS-negative prostate cancer. Oncotarget 2015;6:6235-50.

47. Edgren H, Kangaspeska S, Kallioniemi O. KRAS oncogene rearrangements and gene fusions: unexpected rare encounters in late-stage prostate cancers. Cancer Discov 2011;1:12-3.

48. Wang XS, Shankar S, Dhanasekaran SM, et al. Characterization of KRAS rearrangements in metastatic prostate cancer. Cancer Discov 2011;1:35-43.

49. Qin F, Song Z, Chang M, et al. Recurrent cis-SAGe chimeric RNA, D2HGDH-GAL3ST2, in prostate cancer. Cancer Lett 2016;380:39-46.

50. Kannan K, Wang L, Wang J, et al. Recurrent chimeric RNAs enriched in human prostate cancer identified by deep sequencing. Proc Natl Acad Sci U S A 2011;108:9172-7.

51. Tang Y, Qin F, Liu A, et al. Recurrent fusion RNA DUS4L-BCAP29 in non-cancer human tissues and cells. Oncotarget 2017;8:31415-23.

52. Kluth M, Galal R, Krohn A, et al. Prevalence of chromosomal rearrangements involving non-ETS genes in prostate cancer. Int J Oncol 2015;46:1637-42.

53. Qin F, Song Z, Babiceanu M, et al. Discovery of CTCFsensitive Cis-spliced fusion RNAs between adjacent genes in human prostate cells. PLoS Genet 2015;11:e1005001.

54. Paulo P, Barros-Silva JD, Ribeiro FR, et al. FLI1 is a novel ETS transcription factor involved in gene fusions in prostate cancer. Genes Chromosomes Cancer 2012;51:240-9.

55. Ren S, Peng Z, Mao JH, et al. RNA-seq analysis of prostate cancer in the Chinese population identifies recurrent gene fusions, cancer-associated long noncoding RNAs and aberrant alternative splicings. Cell Res 2012;22:806-21.

56. Zhu Y, Ren S, Jing T, et al. Clinical utility of a novel urinebased gene fusion TTTY15-USP9Y in predicting prostate biopsy outcome. Urol Oncol 2015;33:384.e9-20.

57. Lapuk AV, Wu C, Wyatt AW, et al. From sequence to molecular pathology, and a mechanism driving the neuroendocrine phenotype in prostate cancer. J Pathol 2012;227:286-97.

58. Wyatt AW, Mo F, Wang Y, et al. The diverse heterogeneity of molecular alterations in prostate cancer identified through next-generation sequencing. Asian J Androl 2013;15:301-8.

59. McPherson A, Wu C, Wyatt AW, et al. nFuse: discovery of complex genomic rearrangements in cancer using highthroughput sequencing. Genome Res 2012;22:2250-61. 
60. Wu YM, Su F, Kalyana-Sundaram S, et al. Identification of targetable FGFR gene fusions in diverse cancers. Cancer Discov 2013;3:636-47.

61. Yu YP, Ding Y, Chen Z, et al. Novel fusion transcripts associate with progressive prostate cancer. Am J Pathol 2014;184:2840-9.

62. Rocha J, Zouanat FZ, Zoubeidi A, et al. The Fer tyrosine kinase acts as a downstream interleukin- 6 effector of androgen receptor activation in prostate cancer. Mol Cell Endocrinol 2013;381:140-9.

63. Chen ZH, Yu YP, Tao J, et al. MAN2A1-FER Fusion Gene Is Expressed by Human Liver and Other Tumor Types and Has Oncogenic Activity in Mice. Gastroenterology 2017;153:1120-1132.e15.

64. Annala M, Kivinummi K, Leinonen K, et al. DOT1LHES6 fusion drives androgen independent growth in prostate cancer. EMBO Mol Med 2014;6:1121-3.

65. Wang Y, Wang Y, Liu Q, et al. Comparative RNA-seq analysis reveals potential mechanisms mediating the conversion to androgen independence in an $\mathrm{LNCaP}$ progression cell model. Cancer Lett 2014;342:130-8.

66. Bishop JA, Yonescu R, Epstein JI, et al. A subset of prostatic basal cell carcinomas harbor the MYB rearrangement of adenoid cystic carcinoma. Hum Pathol 2015;46:1204-8.

67. Lai J, An J, Seim I, et al. Fusion transcript loci share many genomic features with non-fusion loci. BMC Genomics 2015;16:1021.

68. Teles Alves I, Hartjes T, McClellan E, et al. Nextgeneration sequencing reveals novel rare fusion events with functional implication in prostate cancer. Oncogene 2015;34:568-77.

69. Sowalsky AG, Xia Z, Wang L, et al. Whole transcriptome sequencing reveals extensive unspliced mRNA in metastatic castration-resistant prostate cancer. Mol Cancer Res 2015;13:98-106.

70. Lindquist KJ, Paris PL, Hoffmann TJ, et al. Mutational Landscape of Aggressive Prostate Tumors in African American Men. Cancer Res 2016;76:1860-8.

71. Tevz G, McGrath S, Demeter R, et al. Identification of a novel fusion transcript between human relaxin-1 (RLN1) and human relaxin-2 (RLN2) in prostate cancer. Mol Cell Endocrinol 2016;420:159-68.

72. Faisal FA, Sundi D, Tosoian JJ, et al. Racial Variations in Prostate Cancer Molecular Subtypes and Androgen Receptor Signaling Reflect Anatomic Tumor Location. Eur Urol 2016;70:14-7.
73. Wang XT, Xia QY, Ni H, et al. Xp11 neoplasm with melanocytic differentiation of the prostate harbouring the novel NONO-TFE3 gene fusion: report of a unique case expanding the gene fusion spectrum. Histopathology 2016;69:450-8.

74. Jaratlerdsiri W, Chan EKF, Petersen DC, et al. Next generation mapping reveals novel large genomic rearrangements in prostate cancer. Oncotarget 2017;8:23588-602.

75. Reeser JW, Martin D, Miya J, et al. Validation of a Targeted RNA Sequencing Assay for Kinase Fusion Detection in Solid Tumors. J Mol Diagn 2017;19:682-96.

76. Afar DE, Vivanco I, Hubert RS, et al. Catalytic cleavage of the androgen-regulated TMPRSS2 protease results in its secretion by prostate and prostate cancer epithelia. Cancer Res 2001;61:1686-92.

77. Jacquinet E, Rao NV, Rao GV, et al. Cloning and characterization of the cDNA and gene for human epitheliasin. Eur J Biochem 2001;268:2687-99.

78. Yordy JS, Li R, Sementchenko VI, et al. SP100 expression modulates ETS1 transcriptional activity and inhibits cell invasion. Oncogene 2004;23:6654-65.

79. Lucas JM, True L, Hawley S, et al. The androgenregulated type II serine protease TMPRSS2 is differentially expressed and mislocalized in prostate adenocarcinoma. J Pathol 2008;215:118-25.

80. Sun C, Dobi A, Mohamed A, et al. TMPRSS2-ERG fusion, a common genomic alteration in prostate cancer activates C-MYC and abrogates prostate epithelial differentiation. Oncogene 2008;27:5348-53.

81. Tomlins SA, Laxman B, Varambally S, et al. Role of the TMPRSS2-ERG gene fusion in prostate cancer. Neoplasia 2008;10:177-88.

82. Kral M, Rosinska V, Student V, et al. Genetic determinants of prostate cancer: a review. Biomed Pap Med Fac Univ Palacky Olomouc Czech Repub 2011;155:3-9.

83. Song C, Chen H. Predictive significance of TMRPSS2ERG fusion in prostate cancer: a meta-analysis. Cancer Cell Int 2018;18:177.

84. Guo C, Stark GR. FER tyrosine kinase (FER) overexpression mediates resistance to quinacrine through EGF-dependent activation of NF-kappaB. Proc Natl Acad Sci U S A 2011;108:7968-73.

85. McPherson A, Hormozdiari F, Zayed A, et al. deFuse: an algorithm for gene fusion discovery in tumor RNA-Seq data. PLoS Comput Biol 2011;7:e1001138.

86. Sboner A, Habegger L, Pflueger D, et al. FusionSeq: a 
modular framework for finding gene fusions by analyzing paired-end RNA-sequencing data. Genome Biol 2010;11:R104.

87. Daniel N, Mihaela S, Henrik E, et al. FusionCatcher - a tool for finding somatic fusion genes in paired-end RNA-sequencing data. bioRxiv 2014. doi: https://doi. org/10.1101/011650.

88. Jia W, Qiu K, He M, et al. SOAPfuse: an algorithm for identifying fusion transcripts from paired-end RNA-Seq data. Genome Biol 2013;14:R12.

Cite this article as: Song C, Chen H. Overview of research on fusion genes in prostate cancer. Transl Cancer Res 2020;9(3):1998-2011. doi: 10.21037/tcr.2020.01.34
89. Iyer MK, Chinnaiyan AM, Maher CA. ChimeraScan: a tool for identifying chimeric transcription in sequencing data. Bioinformatics 2011;27:2903-4.

90. Wijaya E, Shimizu K, Asai K, et al. Referencefree prediction of rearrangement breakpoint reads. Bioinformatics 2014;30:2559-67.

91. Giacomini CP, Sun S, Varma S, et al. Breakpoint analysis of transcriptional and genomic profiles uncovers novel gene fusions spanning multiple human cancer types. PLoS Genet 2013;9:e1003464. 
Table S1 Other fusion genes in prostate cancer

\begin{tabular}{l} 
Fusion gene \\
\hline PMF1-BGLAP, BPTF-KPNA2, RBM14-RBM4, C15orf38-AP3S2, PLEKHO2- \\
ANKDD1A, KIAA1984-C9orf86, GCSH-C16orf46, VMAC-CAPS, ENTPD5-FAM161B, \\
TMC5-CP110, TPD52-MRPS28, IVD-BAHD1, KLK11-KLK7, IRS2-NUFIP1, ZNF763- \\
CHST7, VAMP8-VAMP5, SEC31A-C6orf62, HHLA1-OC1R3, R3HDM2-NFE2, \\
IQCJ-SCHIP1, KRT24-NCOR1, LIN37-GPSN2, NUP214-XKR3, C16orf58-NUPR1, \\
MBPTS1-SERF2, GCN1L1-MSI1, LITAF-DECR2, TGOLN2-USP39, REV1-CPSF3, \\
CAMTA1-SPPL3, DYNC1H1-EIF4B, MBPTS1-SERF2, OGT-RBM22, ROR2-USP36, \\
TIMM9-PRKDC, ZDHHC8-UBL5
\end{tabular}

H2AFJ-HBA2, NEAT1-ANO7, PTMS-TAF15, NEAT1-PCBD2, ENOSF1-KLK3,

作

ZBTB16-KLK3, ZBTB37-GABRB3, CDKN1A-CD9, SOCS4-ERG, DTX2-PMS2L5,

MIER2-RSRC2, LRRFIP2-UBE2D3, TAGLN-SPSB3, FTH1-EIF5A, EEF1D-HDAC5,

ENO1-APCDD1, PTPRN2-SLC25A10, PICK1-SLC16A8, WT-CD9, RYBP-FOXP1,

MIER-RSRC2

ZDHHC7-ABCB9, HJURP-EIF4E2, VWA2-PRKCH, RGS3-PRKAR1B, SPOCK1TBC1D9B, LRP4-FBXL20, INPP4A-HJURP, C16orf70-C16orf48, NDUFV2-

ENSG00000188699, NEAT1-ENSG00000229344, ENSG00000011405-TEAD1,

WDR45L-ENSG00000249026, IMMTP1-IMMT, ENSG00000214009-PCNA,

CTNNA1-ENSG00000249026, LMAN2-AP3S1

CTAGE5-KHDRBS3, SDK1-AMACR, RAD50-PDLIM4, PHF17-SNHG8, DYRK1ACMTM4

TMEM55A-LCLAT1, ABL1-ANXA4, RALGPS1-EXOC6B, DENND1A-ANXA4, ZNF638-KCNS3-PPM1G, GPR107-C2orf28, SLC35D2-LPPR-MRPL50,

$2011 \quad$ Prostate cancer

(37)

LOC199899-JAK1, PRIM1-USP9X, USP9X-PRIM1, DNAJC11-NOTCH2, C140rf145-

MOBP, UGDH-SLC25A31, DENND4A-RAB11A, RAB11A-DENND4A, ZNF410-

PTGR2, SKIV2L2-SV2C, SESN1-MGST2, MLL5-DRAM1

OR51E2-ETV1, 14q133-q21.1-ETV1, SLC45A3/HERVK17/UBTF-ETV4

NDUFAF2-MAST4, PDE4D-FAM172A, PDE4D-PPP2R2B, ADAMTS12-PXDNL, PPP2R2B-FAM172A, PDE4D-C5orf47, CPLX2-UBXD8, EBF1-FBXL17, KCNN2EBF1, RASGRF2-RNF145, JMY-DMGDH, TRIM40-FBXO38, EFNA5-PCDHB7,

YTHDC2-PPP2R2B, PDE8B-UIMC1, ZFP62-RGNEF, EBF1-FEM1C

C12orf76-ANKRD13A, TMEM165-CLOCK, ACTR8-IL17RB, MTG1-LOC619207, KRTCAP3-IFT172, TMEM79-SMG5, NARG1-NDUFC1, SLC44A4-EHMT2, NCAPD3JAM3, SLC16A8-BAIAP2L2, ZNF606-C19orf18

ACSL3-ETV1, FLJ35294-ETV1, FOXP1-ETV1, C15orf21-ETV1, KLK2-ETV4, CANT1- 2015 ETV4, KDM4B-AC011523.1

KLK4-KLKP1, PRKAA1-TTC33, C6orf47-BAG6, MALAT1-WDR74, MALAT1-TTN TBXLR1-PIK3CA, ACPP-PIK3CB, GRHL2-RSPO2

NOS1AP-C1orf226, HARS-ZMAT2, CIQTNF3-AMACR

MIPOL1-ETS, HNRPA2B1-ETV1, MIPOL1-SKIL

ANKRD27-ALDH7A1, ZNF480-ALDH7A1, ELAVL1-ALDH7A1, NR3C1-HOXA9, SLC16A12-TESC, FAM154A-LRP1, IMMP2L-LYST, ENOX1-ANO2, WWOX-

ENOX1, C10rf151-HLCS, HLCS-TTC3, HLCS-ERG, TTC3-CCDC21, TTC3-ERG,

ENSG00000253819-PCNXL2, DISC1-PCNXL2, C110rf41-OR51E2, MLLT4-KIF25,

GPHN-RGS6, GPHN-DPF3, VCL-ZNF503, RGS6-DPF3, ZNF578-EPN1, ANKRD27-

ZNF578, KDM4B-ZNF578, LRP12-ENSG00000253350, ENSG00000254303-

WDR67, PACRG-LOC285796, IPCEF1-PACRG

INTRACHR-SS-OGAP, CHCHD10-VPREB3F, DTD2-HEATR5A, VAMP1-CD27-

AS1, CLN6-CALML4, TMED4-DDX56, NUDT14-JAG2, PRIM1-NACA, ZNF592-

ALPK3, LMAN2-MXD3, BAIAP2L2-SLC16A8, SLC39A1-CRTC2, METTL10-

FAM53B, TFDP1-GRK1, KIAA0753-PITPNM3, CIRBP-C19orf24, TP53RK-SLC13A3,

LINC00680-GUSBP4, PPP1R16A-GPT, ADSL-SGSM3, AKAP8L-AKAP8, AP5S1-

MAVS, DMC1-DDX17, DMKN-KRTDAP, DPM2-PIP5KL1, MED12-NLGN3, RRM2-

C2orf48, SLC29A1-HSP9OAB1, TRADD-B3GNT9, WRB-SH3BGR, BRCA1-VAT1,

DTD2-HEATR5A, RNF4-FAM193

BLVRB-SERTAD3, FAM179B-PRPF39, DDX5-POLG2, GPR108-C3

Intergenic-NBEA, AAK1-AC114772.1, CTA-221G9.11-KIAA1671, POLR1D-LNX2, 2016 RP11-180P8.1-TANC2

SREBF2-XRCC6, FAM117B-BMPR2, GPS2-MPP2, RP11-534G20.3-SVIL, MIPOL1- 2016 $D G K B, R E R E-P I K 3 C D$, Intergenic-AMZ2, CASZ1-KAZN

SREBF2-XRCC6, FAM117B-BMPR2, GPS2-MPP2, RP11-534G20.3-SVIL, MIPOL1- 2016 DGKB, RERE-PIK3CD, Intergenic-AMZ2, CASZ1-KAZN

VWA2-PRKCH, INSL6-JAK2, ZDHHC7-H3F3B, ZDHHC7-UNKI1, HJURP-EIF4E2, PPIP5K2-CTC-340A15.2, ZDHHC7-UNKI2, ZNF577-ZNF841, SPOCK1-Intergenic 